\title{
FUNCTIONAL OUTCOME OF ARTHROSCOPIC RECONSTRUCTION OF ANTERIOR CRUCIATE LIGAMENT TEARS
}

\author{
P. Ashok Kumar ${ }^{1}$, P. Rambabu², K. Srinivasarao ${ }^{3}$, K. Vamsi Krishna ${ }^{4}$, CH. V. Murali Krishna ${ }^{5}$, S. Chandra Sekhar ${ }^{6}$, V. Krishna Swamy7, \\ Jameer Shaik ${ }^{8}$, K. Ramakrishna ${ }^{9}$
}

1 Professor I/c, Department of Orthopaedics, King George Hospital, Andhra Medical College, Visakhapatnam, Andhra Pradesh. ${ }^{2}$ Assistant Professor, Department of Orthopaedics, King George Hospital, Andhra Medical College, Visakhapatnam, Andhra Pradesh. ${ }_{3}^{3}$ Assistant Professor, Department of Orthopaedics, King George Hospital, Andhra Medical College, Visakhapatnam, Andhra Pradesh. ${ }^{4}$ Assistant Professor, Department of Orthopaedics, King George Hospital, Andhra Medical College, Visakhapatnam, Andhra Pradesh. ${ }^{5}$ Assistant Professor, Department of Orthopaedics, King George Hospital, Andhra Medical College, Visakhapatnam, Andhra Pradesh. ${ }_{6}^{6}$ Assistant Professor, Department of Orthopaedics, King George Hospital, Andhra Medical College, Visakhapatnam, Andhra Pradesh. 7 Junior Resident, Department of Orthopaedics, King George Hospital, Andhra Medical College, Visakhapatnam, Andhra Pradesh. $8 J u n i o r$ Resident, Department of Orthopaedics, King George Hospital, Andhra Medical College, Visakhapatnam, Andhra Pradesh. 9Junior Resident, Department of Orthopaedics, King George Hospital, Andhra Medical College, Visakhapatnam, Andhra Pradesh.

\section{ABSTRACT}

\section{BACKGROUND}

Anterior Cruciate Ligament (ACL) tear is the most common serious ligamentous injury to the knee joint. Anterior Cruciate Ligament (ACL) injury is quite common among young active population, athletes and contact sports. The exact incidence of anterior cruciate ligament tears is not known as the cases are being under reported. The ACL is the primary stabilizer against anterior translation of the tibia on the femur and is important in counteracting rotation and valgus stress.

\section{MATERIALS AND METHODS}

Between November 2012 to October 2014, 34 consecutive patients who underwent arthroscopic assisted ACL reconstructions in the Department of Orthopedics and Traumatology, King George Hospital, Visakhapatnam were the material in our study. Age groups between 18 to 45 years considered. We utilised both BPTB and Quadrupled hamstring graft depending on the patient's age, outcome testing in all cases was performed at the latest follow-up (at least 6 months). Post-operative physiotherapy rehabilitation protocol followed for 06 months.

\section{RESULTS}

Standard protocol of Lysholm and IKDC knee scoring system were used for evaluation of the results of the surgery during followup. Patients were evaluated periodically at preop, 3 months, 6 months, 12 months, 18 months and 24 months.

\section{CONCLUSION}

Patients with isolated ACL injury had better outcome compared to patients who underwent associated meniscectomy. Most common mechanism of injury was activity of sports in 20 patients. Postoperatively at 3 months, anterior drawer's was $1+$ in 6 , 29 (85.2\%) patients had normal range of motion; 29 (85.29\%) patients had 5/5 quadriceps power (MRC grading) 94\% of them had 5/5 power at latest followup. No significant difference between outcomes of BPTB and Hamstrings graft. Functional outcome of our study were similar to the previously published studies.

\section{KEYWORDS}

ACL Tear, Reconstruction, Physiotherapy, Scoring Systems, BPTB, Hamstring Graft.

HOW TO CITE THIS ARTICLE: Kumar PK, Rambabu P, Srinivasarao K, et al. Functional outcome of arthroscopic reconstruction of anterior cruciate ligament tears. J. Evolution Med. Dent. Sci. 2016;5(10):427-432, DOI: 10.14260/jemds/2016/98

\section{INTRODUCTION}

Anterior Cruciate Ligament (ACL) tear is the most common serious ligamentous injury to the knee joint. ${ }^{1}$ Anterior Cruciate Ligament (ACL) injury is quite common among young active population, athletes and contact sports. ${ }^{2}$ The exact incidence of anterior cruciate ligament tears is not known as the cases are being under-reported. The goals of reconstruction are to restore stability to the knee, allow the patient to return to normal activities including sports and to delay the onset of osteoarthritis with associated recurrent injuries to the articular cartilage and loss of meniscal functions. ${ }^{3}$

The ACL is the primary stabilizer against anterior

Financial or Other, Competing Interest: None.

Submission 18-11-2015, Peer Review 23-11-2015,

Acceptance 26-11-2015, Published 04-02-2016.

Corresponding Author:

Dr. P. Ashok Kumar,

\# B-98, Dayal Nagar,

Visakhapatnam-530043, Andhra Pradesh.

E-mail: ashok_ortho59@rediffmail.com

DOI: $10.14260 / \mathrm{jemds} / 2016 / 98$ translation of the tibia on the femur and is important in counteracting rotation and valgus stress. Anterior cruciate ligament deficiency leads to knee instability. ${ }^{4}$ this results in recurrent injuries and increased risk of intra-articular damage, especially the meniscus. During the past decade, arthroscopically assisted techniques have been an accepted method of reconstructing the ACL.5,6,7 There is little or no difference between bone-patellar tendon-bone and combined semitendinosus and gracilis tendon grafts in terms of the functional outcome after ACL reconstruction despite greater laxity measurements in the hamstring tendon group patients. ${ }^{8}$ Graft choice, surgeon experience, correct graft position, choice of graft fixation and postoperative rehabilitation confound the results of comparison of ACL reconstruction.9,10,11 Stiffness and strength tend to be slightly better with bone-patellar tendonbone, but overall results are comparable.

The advantages of arthroscopically assisted anterior cruciate ligament reconstruction include elimination of capsular incisions, decrease in trauma to the fat pad, avoidance of desiccation of the articular cartilage, better visualization of the femoral attachment and a lower incidence of postoperative patello-femoral pain than with open 
reconstruction. ${ }^{11}$ Similar to all arthroscopic techniques, the primary disadvantage of arthroscopically assisted ACL reconstruction is that the technique has a long learning curve and is a technically demanding procedure. ${ }^{9}$

The bone-patellar tendon-bone and the hamstring tendon are the two most commonly used autografts for reconstruction.12,13,14,15,16 The bone-patellar tendon-bone graft has been widely accepted as gold standard for ACL reconstruction with high success rate. ${ }^{17,18,19}$ However, donor site morbidities and extensor mechanism problems associated with bone-patellar tendon-bone graft have led to increasing popularity of hamstring tendon graft, which also had better cosmoses. 20

In our study, we have analyzed the results of Arthroscopic ACL Reconstruction using autologous ipsilateral bone patellar tendon bone graft and quadrupled hamstring graft.

\section{AIMS AND OBJECTIVES \\ THE AIM OF THE STUDY}

Evaluation of the results of arthroscopic guided anterior cruciate ligament reconstruction.

\section{OBJECTIVES}

To know the functional outcome of arthroscopic guided anterior cruciate ligament reconstruction using Lysholm knee score and IKDC score.

To list and evaluate the complications encountered with anterior cruciate ligament reconstruction.

To analyze the results and compare the same with standard published data in literature.

We want to analyze the results of arthroscopic ACL reconstruction using autologous ipsilateral bone patellar tendon bone graft and quadrupled hamstring graft.

\section{MATERIALS AND METHODS}

Between November 2012 to October 2014, 34 consecutive patients who underwent arthroscopic assisted ACL reconstructions in the Department of Orthopedics and Traumatology, King George Hospital, Visakhapatnam, were the material in our study.

No. of Cases: $\quad 34$ cases

Duration of Study: November 2012 to October 2014

\section{Inclusion Criteria}

All patients with ACL Tear...

Who are in the age groups between 18 to 45 years?

With history of repeated and episodic knee instability (ACL tear),

With no evidence of clinical and radiological degenerative change in the knee.

\section{Exclusion Criteria Included}

Patients with ACL tear in age groups less than 18 and greater than 45 years.

Patients with ACL tears with associated injuries of tibial or femoral condyles.

Patients with ACL tears with tri-compartmental osteoarthritis of knee joint.

Contralateral ACL deficiency.

Bilateral ACL reconstruction.

Revision ACL surgery.

Previous knee surgeries.

Concomitant extra-articular reconstruction.

Comorbid conditions.

\section{METHODS}

After the patients are clinically and radiologically diagnosed to have ACL tear and after meeting inclusion criteria, the patients were taken up for arthroscopic ACL reconstruction. All the patients followed standard physiotherapy protocol.
We utilised both BPTB and Quadrupled hamstring graft at random depending on the patient's age, physical activity, occupation. Standardised postoperative rehabilitation protocol were followed for 6 months. The outcome testing in all cases were performed at the latest follow-up (at least 6 months). In all the patients, graft was fixed with titanium interference screws on femoral and tibial side.

\section{OBSERVATIONS AND RESULTS}

In our study of Arthroscopic Anterior Cruciate Ligament reconstruction, a total of 34 cases were operated and followed up. Minimum followup period was six months and maximum followup period was twenty four months, average being 14 months.

\section{AGE DISTRIBUTION}

\begin{tabular}{|c|c|c|}
\hline $\begin{array}{c}\text { AGE GROUP } \\
\text { (YRS) }\end{array}$ & $\begin{array}{c}\text { NO. OF PATIENTS } \\
\text { (BPTB; STG) }\end{array}$ & PERCENTAGE \\
\hline $\mathbf{1 8 - 2 4}$ & $14(05 ; 10)$ & $44.11 \%$ \\
\hline $\mathbf{2 5 - 3 1}$ & $09(02 ; 07)$ & $26.41 \%$ \\
\hline $\mathbf{3 2 - 3 8}$ & $05(03 ; 02)$ & $14.7 \%$ \\
\hline $\mathbf{3 9 - 4 5}$ & 05(02;03) & $14.7 \%$ \\
\hline \multicolumn{3}{|c|}{ Table 1: Age Group (n=34) } \\
\hline
\end{tabular}

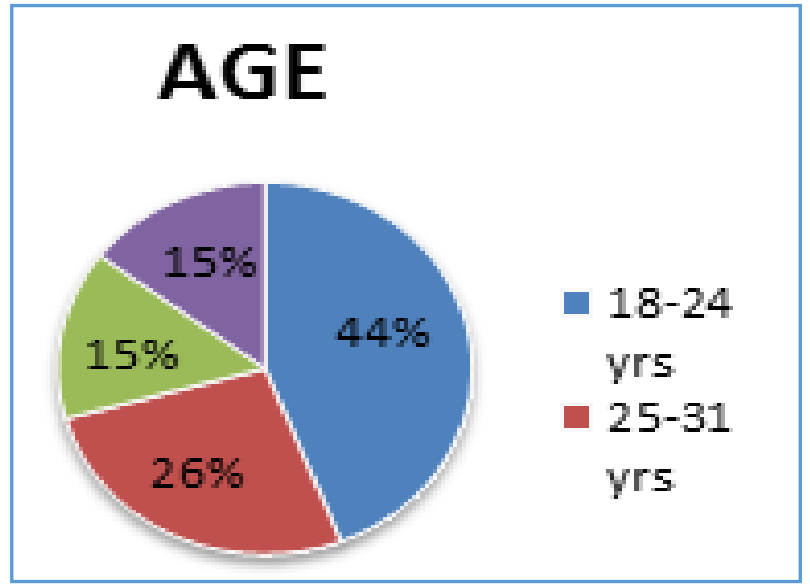

Fig. 1: Pie Diagram showing the Age Groups

\section{SEX DISTRIBUTION. 17}

Male predominance was found in our study; 34 (97.1\%) patients were males and one $(2.9 \%)$ female patient was present. This probably because males are more frequently involved in sports and road traffic accidents.

\section{LATERALITY}

Left knee was affected in $13(33.33 \%)$ patients and right knee was affected in $17(66.66 \%)$ patients. There was not much difference in lateralization of the injury.

\section{ASSOCIATED INJURIES}

Nineteen patients in our study had isolated ACL tears. Two patients had associated lateral meniscal tears, eleven patients had medial meniscal tears and one patient had both medial and lateral meniscus tear. All 14 patients had undergone arthroscopic meniscectomy at the time of reconstruction. Patients with isolated ACL injuries had better post-operative knee functional score compared to those with associated injuries.

\section{AVERAGE LYSHOLM SCORE}

We have used the Lysholm score and IKDC score for subjective evaluation of all our patients at each followup. The following are the parameters and the maximum points given for each. Parameters (100 points).

Limp (5 points)

Support (5 points)

Stair climbing (10 points) 
Squatting

Instability

(5 points)

(30 points)

(30 points)

Swelling (10 points)

Locking (5 points)

In our study Lysholm score was done at preop, 3 months, 6 months, 1 year, 18 months and 2 years. Average Lysholm score at preop 56.44, at 3 months 79.9, at 6 months 88.17, at 1 year 92.92, 18 months 94.73 and at 2 years 94.0. There was clinically significant improvement in Lysholm score preoperative period (56.44) to 6 months post-operative period (88.17).

\begin{tabular}{|c|c|}
\hline \multicolumn{2}{|c|}{ GRADING OF LYSHOLM SCORE } \\
\hline Poor & $<65$ points \\
\hline Fair & oints \\
\hline ai & ints \\
\hline lle & 93 \\
\hline 16 & סמ \\
\hline
\end{tabular}

\begin{tabular}{|c|c|}
\hline DURATION & $\begin{array}{c}\text { AVERAGE LYSHOLM } \\
\text { SCORE } \\
\text { (BPTB;STG) }\end{array}$ \\
\hline Preop $(\mathrm{n}=34)$ & $56.44(54.1 ; 57.6)$ \\
\hline 3 months $(\mathrm{n}=34)$ & $79.9(78.5 ; 80.7)$ \\
\hline 6 months $(\mathrm{n}=34)$ & $88.1(86.5 ; 89.0)$ \\
\hline 1 year $(\mathrm{n}=26)$ & $92.92(93.5 ; 92.4)$ \\
\hline 18 months $(\mathrm{n}=19)$ & $94.73(95.8 ; 93.7)$ \\
\hline 2 years $(\mathrm{n}=4)$ & $94.0(97.5 ; 90.5)$ \\
\hline \multicolumn{2}{|c|}{ Table 2: Average Lysholm Score $(\mathbf{n}=\mathbf{3 4})$} \\
\hline
\end{tabular}

\section{AVERAGE IKDC SCORE}

\begin{tabular}{|c|c|}
\hline DURATION & AVERAGE IKDC SCORE \\
\hline Preop $(n=34)$ & $54.94(53.6 ; 55.63)$ \\
\hline 3 months $(n=30)$ & $75.5(73.0 ; 76.18)$ \\
\hline 6 months $(n=30)$ & $85.5(83.9 ; 86.36)$ \\
\hline 1 year $(n=21)$ & $89.38(90.3 ; 88.54)$ \\
\hline 18 months $(n=20)$ & $95(95.44 ; 94.0)$ \\
\hline 2 years & $94(98,93)$ \\
\hline \multicolumn{2}{|c|}{ Table 3: Average IKDC Score } \\
\hline
\end{tabular}

\begin{tabular}{|c|c|}
\hline TEST RESULT & $\begin{array}{c}\text { NO. OF PATIENTS } \\
\text { (BPTB;STG) }\end{array}$ \\
\hline NEGATIVE & $28(10 ; 18)$ \\
\hline $1+$ & $6(02 ; 04)$ \\
\hline Table 4: Anterior Drawer Test at 3 Months \\
Follow-up (n=34)
\end{tabular}

\begin{tabular}{|c|c|}
\hline TEST RESULT & $\begin{array}{c}\text { NO. OF PATIENTS } \\
\text { (BPTB;STG) }\end{array}$ \\
\hline NEGATIVE & $33(12 ; 21)$ \\
\hline $1+$ & $1(0 ; 1)$ \\
\hline Table 6: Anterior Drawer Test at \\
1 Year Follow-up $(\mathrm{n}=30)$
\end{tabular}

Anterior drawer test was negative in 33 (97.0\%) patients. These patients had no instability at 1 year followup during activities like running or climbing up and down stairs; 1 patient $(2.9 \%)$ had $1+$ laxity. This patient had no instability while walking. None of the patients had pivot shift test positive.

\section{RANGE OF MOTION OF OPERATED KNEE}

In our study of 34 patients at 3 months followup, 29 (85.2\%) patients had normal range of motion of the operated knee at 6 months followup; 31 (91.17\%) patients had equal range of motion compared to normal contralateral side at 1 year followup; 32 (94.11\%) patients had equal range of motion compared to contralateral side; 1 patient had deep infection with loss of range of motion.

\section{QUADRICEPS POWER}

At 3 months followup, 29 patients (85.29\%) had grade of 5/5 power in Quadriceps. At 6 months, 30 patients (88.23\%) had grade $5 / 5$ power. At 1 year followup, 18 patients $(90.0 \%)$ out of 20 had grade $5 / 5$ power.

This shows that there was significant improvement in Quadriceps muscle strength at long-term followup with good rehabilitation program; 2 patients $(6.7 \%)$ had grade $3 / 5$ power, one patient had deep infection which was treated and power improved to $4 / 5$ at latest followup.

\section{DISCUSSION}

The present study of Arthroscopic guided Anterior Cruciate Ligament Reconstruction using BPTB graft and Quadrupled hamstring graft was done during the period of November 2012 to October 2014, at Andhra Medical College and King George Hospital, Visakhapatnam. Outcome was measured using Lysholm knee score, IKDC Score, Anterior drawer test, Range of motion of the knee joint and Quadriceps power of ipsilateral knee. And result of the present study was compared with the studies of D Choudhary et al. 2005, Jomha et al. 1999, Riley et al. 2004 and Mahir et al. 2005.

\begin{tabular}{|c|c|c|c|c|}
\hline $\begin{array}{c}\text { Author \& Year of } \\
\text { Publisher }\end{array}$ & Graft Used & Technique & $\begin{array}{c}\text { Femoral } \\
\text { Fixation }\end{array}$ & Tibial Fixation \\
\hline $\begin{array}{c}\text { D Choudhary et al. } \\
2005\end{array}$ & $\begin{array}{c}\text { Ipsilateral } \\
\text { autogenous BPTB }\end{array}$ & $\begin{array}{c}\text { Arthroscopic } \\
\text { single incision }\end{array}$ & $\begin{array}{c}\text { Interference } \\
\text { screw }\end{array}$ & Interference screw \\
\hline Jomha 1999 & $\begin{array}{c}\text { Ipsilateral } \\
\text { autogenous BPTB }\end{array}$ & $\begin{array}{c}\text { Arthroscopic } \\
\text { single incision }\end{array}$ & $\begin{array}{c}\text { Interference } \\
\text { screw }\end{array}$ & Interference screw \\
\hline Railey et al. 2004 & $\begin{array}{c}\text { Four stranded } \\
\text { Hamstring graft }\end{array}$ & $\begin{array}{c}\text { Arthroscopic } \\
\text { single incision }\end{array}$ & Endobutton & $\begin{array}{c}\text { Staples, washer and } \\
\text { screw }\end{array}$ \\
\hline Mahir et al. 2005 & $\begin{array}{c}\text { Four stranded } \\
\text { hamstring graft }\end{array}$ & $\begin{array}{c}\text { Arthroscopic } \\
\text { single incision }\end{array}$ & Cross pin & Interference screw \\
\hline Our Study & $\begin{array}{c}\text { Ipsilateral } \\
\text { autogenous BPTB } \\
\text { four stranded } \\
\text { hamstring graft }\end{array}$ & $\begin{array}{c}\text { Arthroscopic } \\
\text { single incision }\end{array}$ & $\begin{array}{c}\text { Interference } \\
\text { screw }\end{array}$ & Interference screw \\
\hline \multicolumn{4}{|c|}{ Table 7: Surgical Protocol } \\
\hline
\end{tabular}




\begin{tabular}{|c|c|c|c|c|c|}
\hline $\begin{array}{c}\text { Author \& Year of } \\
\text { Publisher }\end{array}$ & $\begin{array}{c}\text { No. of } \\
\text { Patients }\end{array}$ & Followup & $\begin{array}{c}\text { Mean age at } \\
\text { Surgery }\end{array}$ & $\begin{array}{c}\text { Mean Followup } \\
\text { Interval (mo) }\end{array}$ & Gender \\
\hline Jomha 1999 & 59 & $74 \%$ & 26 Years & 84 & $73 \%$ Male \\
\hline $\begin{array}{c}\text { D Choudhary et al. } \\
2005\end{array}$ & 100 & $78 \%$ & 27 Years & 12 & $93 \%$ Male \\
\hline Railey et al. 2004 & 85 & $70 \%$ & 33 Years & 24 & $59 \%$ Male \\
\hline Mahir et al. 2005 & 62 & $100 \%$ & 24 Years & 18 & $100 \%$ Male \\
\hline $\begin{array}{c}\text { Our Study } \\
\text { (BPTB;STG) }\end{array}$ & $\begin{array}{c}34 \\
(12 ; 22)\end{array}$ & $76 \%$ & $\begin{array}{c}27 y r s \\
\text { (28.6yrs;26.5yrs) }\end{array}$ & 14 & $97.1 \%$ Male \\
\hline \multicolumn{7}{|c|}{ Table 8: Patient Variables } \\
\hline
\end{tabular}

Average age at surgery in the present study group was 27 years and that of D Choudhary et al. was 27 years and that of Jomha et al. was 26 years and Railey et al. was 33 years and Mahir et al. was 24 yrs.

Average duration of follow-up of the present study was 14 months with a minimum follow-up period 6 months and maximum follow-up period was 24 months. Average duration of follow-up of D Choudhary et al. was 12 months and that of Jomha et al. was 84 months, Railey et al. was 24 months, Mahir et al. was 18 months.

\begin{tabular}{|c|c|}
\hline Author \& Year of Publisher & Average Lysholm Score \\
\hline D Choudhary et al. 2005 & 92 \\
\hline Jomha 1999 & 94 \\
\hline Railey et al. 2004 & 91 \\
\hline Mahir et al. 2005 & 93.5 \\
\hline \multicolumn{2}{|c|}{$\begin{array}{c}\text { Our Study } \\
\text { (BPTB;STG) }\end{array}$} \\
\hline \multicolumn{2}{|c|}{ Table 9: Lysholm Knee Score } \\
\hline
\end{tabular}

The measured Lysholm score of D Choudhary et al. at the end of the study was 92, Jomha et al. at the end of the study was 94, Railey et al. at the end of the study was 91, Mahir et al. was 93.5 and in our study average Lysholm score at last followup was 90 .

\begin{tabular}{|c|c|c|c|c|}
\hline Author and & \multicolumn{5}{|c|}{ Postoperative Grade (\%) } \\
\cline { 2 - 5 } Year Published & $\mathbf{0}$ & $\mathbf{1 +}$ & $\mathbf{2 +}$ & $\mathbf{3 +}$ or 4+ \\
\hline $\begin{array}{c}\text { D Choudhary } \\
\text { et al. 2005 }\end{array}$ & 95 & 4 & 1 & 0 \\
\hline Jomha 1999 & 76 & 22 & 1 & 0 \\
\hline Railey et al. 2004 & 89 & 7 & 4 & 0 \\
\hline Mahir et al. 2005 & 100 & 0 & 0 & 0 \\
\hline Our Study & 100 & 0 & 0 & 0 \\
\hline Table 10: Pivot Shift Examination \\
\hline
\end{tabular}

In the present study, no patient had Pivot Shift test positive postoperatively.

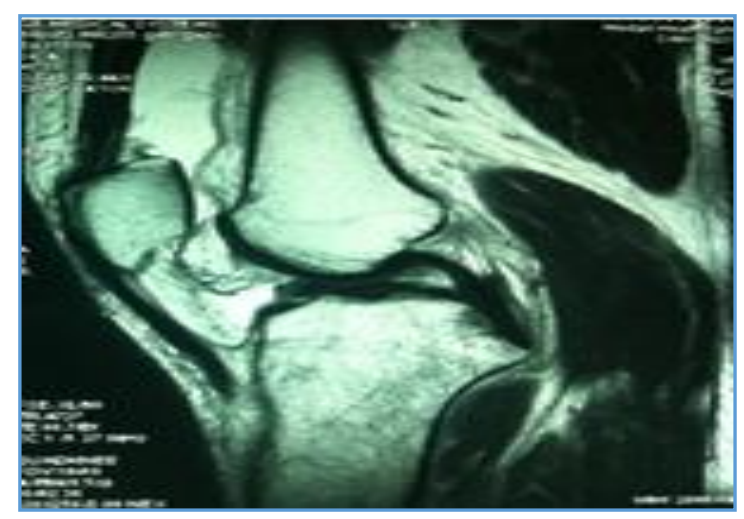

MRI Scan

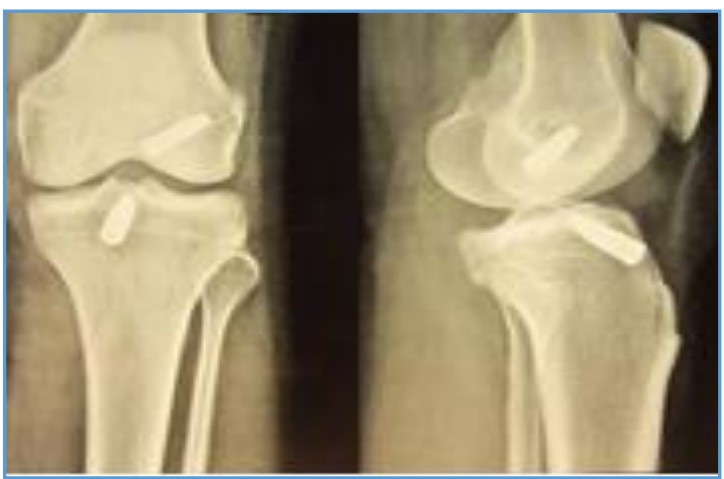

Postop Radiograph

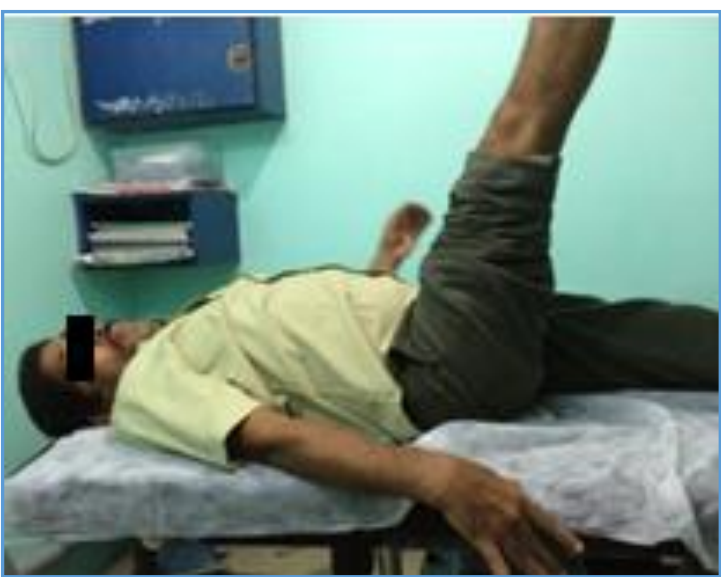

Postop Straight Leg Raising

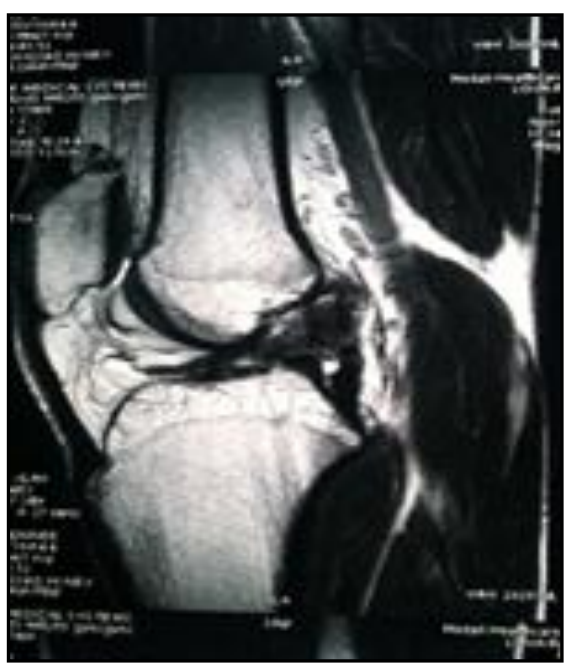

MRI Scan 


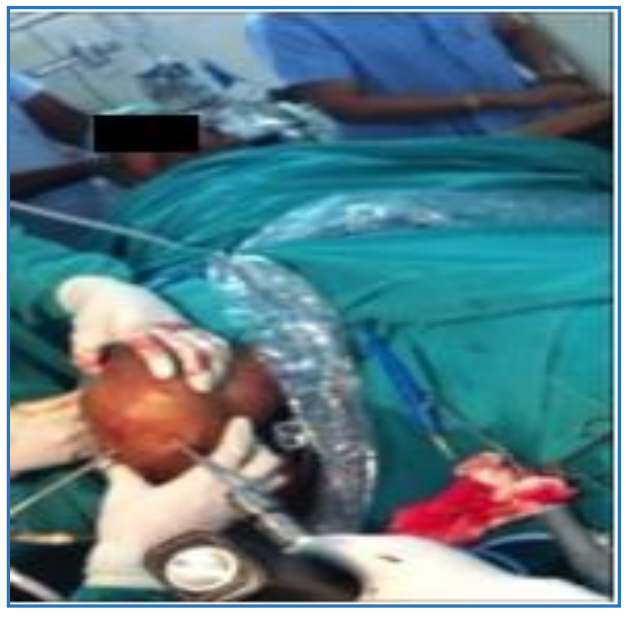

Intraoperative Photo

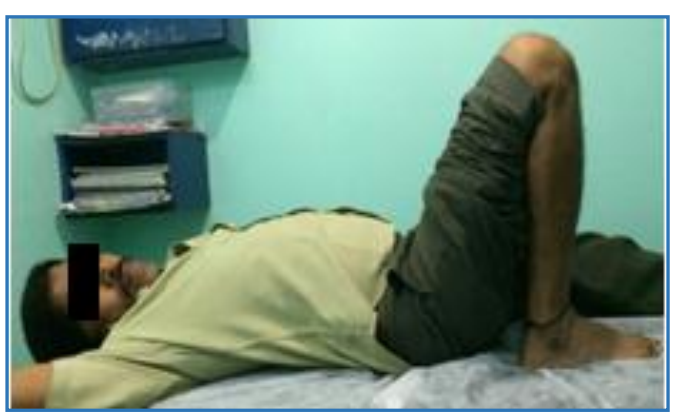

Postoperative knee flexion

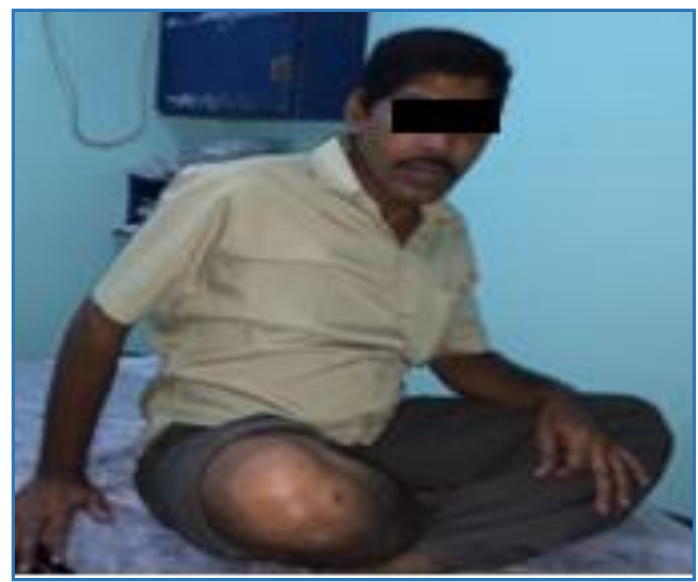

Postoperative Cross Leg Sitting

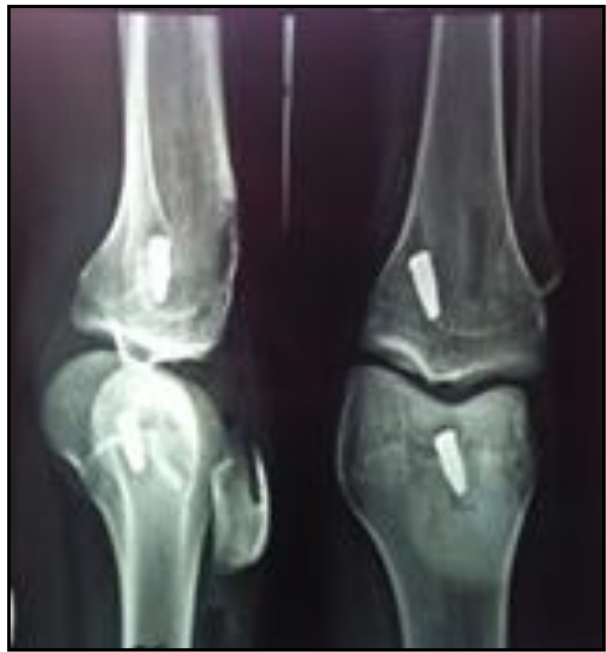

Postoperative Radiograph

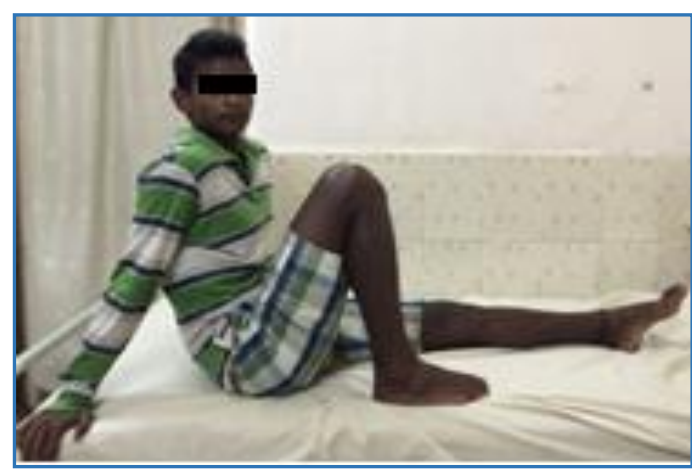

Postoperative Knee Flexion

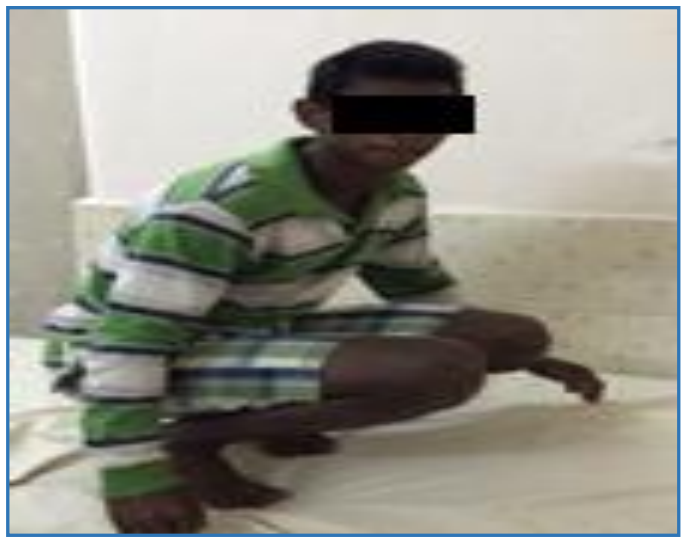

Postoperative Squatting

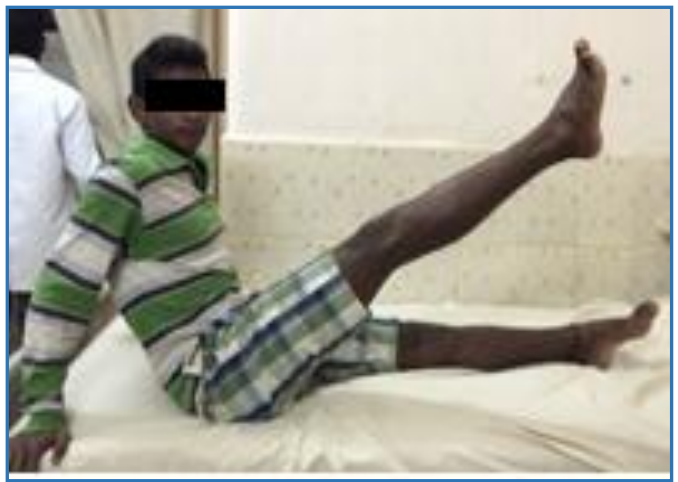

Postoperative Knee Extension

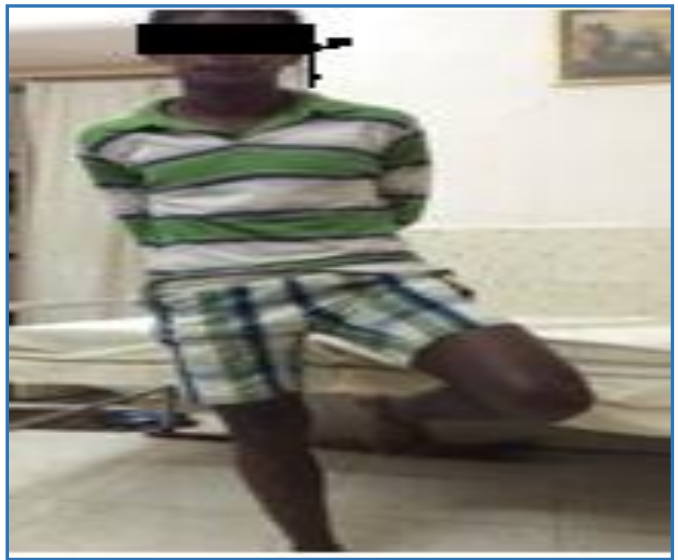

Postoperative Weight Bearing

\section{COMPLICATIONS AND REOPERATION}

Jomha et al. 1999 reported six patients with graft failure, screw removal in seven patients. Manipulation under anesthesia in 
three patients, Arthroscopic division of adhesions in two patients. One patient with deep infection was treated with lavage and screw removal.

Railey et al. 2004 reported six patients with traumatic rupture of graft, five of which were revised arthroscopically and one was treated with knee stabilization brace. Two patients with deep infection were treated with arthroscopic irrigation and debridement, intravenous and oral antibiotics and rehabilitation.

D Choudhary et al. 2005 had not reported any graft failure or deep infection. They reported most common complication as anterior knee pain and most common immediate complication as screw divergence.

Mahir et al. 2005 have not reported any complications in their study.

In the present study, we had a patient with deep infection who was treated with arthroscopic screw removal, joint lavage and debridement, IV antibiotics and prolonged oral antibiotics and rehabilitation. Two patients developed superficial infection, which was treated by oral antibiotics and regular dressings. Three patients developed anterior knee pain.

\section{CONCLUSIONS}

Majority of study subjects were males, i.e. 33 out of 34 .

Mean age was 27 years.

Only nineteen patients had isolated ACL injury, remaining fifteen patients had ACL associated injuries.

Patients with isolated ACL injury had better outcome compared to patients who underwent associated meniscectomy.

Right side was affected in 22 patients and left side in 9 patients.

Most common mechanism of injury was activity of sports in 20 patients, injuries during RTA in 10 patients and others (work related, daily activities) injuries in 4 patients.

There is significant pre-operative to post-operative improvement in knee functional scores both Lysholm and IKDC.

Postoperatively at 3 months anterior drawers was $1+$ in $6(17.64 \%)$ patients, which improved with rehabilitation in all patients.

Postoperatively at 3 months $29(85.2 \%)$ patients had normal range of motion.

Postoperatively at 3 months, 29 (85.29\%) patients had $5 / 5$ quadriceps power (MRC grading), $94 \%$ of them had 5/5 power at latest followup.

In our study, we had complications like Anterior Knee Pain, Superficial infection and Deep infection which were treated accordingly.

Autologous ipsilateral bone patellar tendon bone graft and quadrupled hamstring graft have produced good-toexcellent post-operative functional scores which were clinically significant.

There is no significant difference between outcomes of BPTB and Hamstrings graft.

Functional outcome of our study were similar to the previously published studies.

\section{REFERENCES}

1. Miyasaka KC, Daniel DM, Stone ML. The incidence of knee ligament injuries in the general population. Am J Knee Surg 1991:4:3-8

2. Jorgensen U, Sonne-Holm, Lauridsen F, et al. Long-term follow-up of meniscectomy in athletes. J Bone Joint Surg (Br) 1987;69:80-3.

3. Rangger C, Klestil T, Gloetzer W, et al. Osteoarthritis after arthroscopic partial meniscectomy. Am J Sports Med 1995;23:240-4.
4. Dye SF, Wojtys EM, Fu FH, et al. Factors contributing to function of the knee joint after injury and reconstruction of the anterior cruciate ligament. In Zuckerman JD. Ed. Instructional Course Lecture. Rosemont, American Academy of Orthopedic Surgery 1999;48:185-98.

5. Jomha NM, Pinczewski LA, Clingeleffer $A$, et al. Arthroscopic reconstruction of anterior cruciate ligament with patellar-tendon autograft and interference screw fixation. The results at seven years. J Bone Joint Surg (Br) 1999;81:775.

6. Barrack RL, Bruckner JD, Knist J, et al. The outcome of non-operatively treated complete tears of the anterior cruciate ligament in active young adults. Clin Orthop 1990;259:192-9.

7. Single versus two incision arthroscopic anterior cruciate ligament reconstruction. J Arthroscopy 1996;12:462-9.10.

8. Buss DD, Warren RF, Wickiewicz TJ, et al. Arthroscopically assisted reconstruction of the anterior cruciate ligament with use of autogenous patellar ligament grafts. Results after twenty-four to forty-two months. J Bone Joint Surg (Am) 1993;75:1346-5.

9. Barry B Phillips, Campbell's operative orthopedics, tenth edition, ch: 48.

10. Fu FH, Schulte KR. Anterior cruciate ligament surgery 1996. State of the art. Clin Orthop 1996;325:19-24.

11. Meade TD, Dickson TB. Technical pitfalls of a single incision arthroscopic ACL reconstruction. Am J Arthroscopy 1992;2:15-9.

12. Shaieb MD, Kan DM, Chang SK, et al. A prospective randomized comparison of patellar versus semitendinosus and Gracilis tendon autografts for anterior cruciate ligament reconstruction. Am J Sports Med 2002;30:214-20.

13. Barrett GR, Noojin FK, Hartzog CW, et al. Reconstruction of the anterior cruciate ligament in females. A comparison of hamstring versus patellar tendon autograft. Arthroscopy 2002;18:46-54.

14. Ejerhed L, Kartus J, Sernert N, et al. Patellar tendon or semitendinosus tendon autografts for ACLR: a prospective randomized study with a two-year followup. Am J Sports Med 2003;31:19-25.

15. Jansson KA, Linko E, Sandelin J, et al. A prospective randomized study of patellar versus hamstring tendon autografts for anterior cruciate ligament reconstruction. Am J Sports Med 2003;31:12-8.

16. Pinczewski LA, Deehan DJ, Salmon LJ, et al. A five-year comparison of patellar tendon versus four-strand hamstring tendon autograft for arthroscopic reconstruction of the ACL.

Am J Sports Med 2002;30:523-36.

17. Beynnon BD, Johnson RJ, Fleming, et al. Anterior cruciate ligament replacement: comparison of bone-patellar tendon-bone grafts with two strand hamstring grafts. J Bone Joint Surg (Am) 2002;84:1503-13.

18. Aglietti P, Buzzi R, Zaccherotti G, et al. Patellar tendon versus doubled semitendinosus and Gracilis tendons for anterior cruciate ligament reconstruction. Am J Sports Med 1994;22:211-8.

19. Marder RA, Raskind JR, Carroll M. Prospective evaluation of arthroscopically assisted anterior cruciate ligament reconstruction. Patellar tendon versus semitendinosus and Gracilis tendons. Am J Sports Med 1991;19:478-84.

20. Romano VM, Graf BK, et al. (1993). "Anterior cruciate ligament reconstruction. The effect of tibial tunnel placement on range of motion." American Journal of Sports Medicine 21(3):415-8, 1993 May 21(3):415-8. 